\title{
Investigation on influence of stamp forming parameters on formability of thermoplastic composite
}

\author{
Sugumar Suresh ${ }^{1 *}$ and Velukkudi Santhanam Senthil Kumar ${ }^{2}$ \\ ${ }^{1}$ Velammal Engineering College, Mechanical Engineering, Anna University, Chennai, Tamil Nadu, India \\ ${ }^{2}$ College of Engineering Guindy, Mechanical Engineering, Anna University, Chennai, Tamil Nadu, India \\ *deva.suresh78@gmail.com, vssk70@gmail.com
}

\begin{abstract}
Advanced fabric reinforced polymer composites find extensive applications in aerospace and structural fields due to their high mechanical properties. A novel stamp forming technique finds extensive use in the hemispherical forming of thermoplastic composites. This study investigates the influence of stamp forming parameters on the formability of thermoplastic composite using Taguchi's robust design and grey relational analysis. Taguchi's orthogonal array was used for designing the forming experiments. Responses such as forming ratio and logarithmic thickness strain were considered for the assessment of sheet formability through single and multi-response optimization. Analysis of variance was used for the determination of the contribution of each parameter on formability and it was identified that the die temperature acts as a prominent factor, followed by blank holder force and blank temperature. The confirmation test was conducted at optimum parameter levels and the obtained experimental grade was seen within the confidence interval of the predicted value.
\end{abstract}

Keywords: thermoplastic composite, stamp forming, sheet formability, grey relational analysis, optimization.

\section{Introduction}

At present, advanced glass fabric reinforced thermoplastic (GFRTP) composites are found as substitutes for metals and thermoset composites due to their better impact, corrosion-resistance and fracture toughness properties ${ }^{[1]}$. The major driver of growth for the fabric reinforced thermoplastic composite in aerospace, automotive and sporting goods industries is the increasing requirement of recyclable, lightweight, and environment friendly products ${ }^{[2]}$. The higher durability feature of thermoplastic composites made them better suitable for crash applications than the thermoset composites. For mass production, the final product which yields a potential thermoplastic composite, can possibly be melt-shaped for fast and programmed processing. In thermoplastic composites, the advantages of stiff fibres are combined with those of the ductile thermoplastic matrix ${ }^{[3]}$.

Currently, automotive industries are discovering novel and cost-effective processing technologies particularly in the field of press forming, tape laying and winding processes. The type of matrix and reinforcing materials determines the processing methods to be used. The processing techniques that have surfaced recently have utilized these advanced fabric reinforced composites to form complex-shaped parts for large volume production ${ }^{[4]}$. Stamp forming is widely seen as a fastest technique involving the deformation of the solid sheet material. Stamp forming is not well suited for thermosetting composites, as the molecular structure of the thermoset does not permit the material flow. This stamp forming approach is very well established as ideal for the forming of woven fabric-reinforced thermoplastic composites. As the temperature approaches the melting point of the matrix, the thermoplastic composites can be softened with the ability to flow to fit into the die cavity ${ }^{[5]}$. Instabilities like buckling and wrinkling may occur during the formation of the woven fabric-reinforced composites into dome shaped parts. The processing parameters which mostly control the forming characteristics of stamp formed components, require optimization for the purpose of controlling the occurrence of wrinkling and other defects ${ }^{[6]}$.

Nurul Fazita et al. ${ }^{[7]}$ studied the impact of parameters on the existence of deformations in fabric reinforced poly-lactic-acid polymer composites and identified that the hot tooling conditions would provide better-quality domes. They observed the larger significance of wrinkles in the wrap direction of the composite domes in contrast with the weft direction. The influence of four parameters on the degree of crystallinity, shear strength, and part thickness were evaluated by Lessard et al. ${ }^{[8]}$. They found a notable contribution on part consolidation made by the stamping pressure and mold temperature. The emphasis of Ma et al. ${ }^{[9]}$ was on the progress of a new stamping method for fiber reinforced polymers and optimized the process parameters using Taguchi's split-plot designs. The outcomes depicted the correlation between the processing parameters and the shear stress. Zhu et al. ${ }^{[10]}$ noticed the shear distribution during the forming as the outcome of both the sheet orientation and the mold shape. They carried out experiments on the optimization for the holding force, mold shape, forming temperature, sheet orientation and stamping speed.

The influence of parameters on the formability of composites was investigated by Venkatesan and 
Kalyanasundaram ${ }^{[1]}$ who identified the preheat temperature as the most significant factor in controlling the formability of composites, followed by the blank holder force for achieving quality parts. Kalyanasundaram et al. ${ }^{[12]}$ studied the forming behavior of fiber metal laminates using the design of experiments technique, for understanding the effects of process parameters. They have presented the changes in formability of the materials by the recrystallization behavior. Vanclooster et al. ${ }^{[13]}$ evaluated the influence of parameters on the formation of wrinkling and spring back using the fractional factorial design. The conclusion was that a high preheat temperature, a high deep drawing speed, a medium blank holder pressure, a low tool temperature and the expansion of additional polypropylene between the layers prompted a wrinkle free and full-grown composite. Lee et al. ${ }^{[14]}$ did analysis of the impact of blank holding force on the shapes formed on non-crimp fabrics during the stamp forming process. Many researchers have done experimental and numerical formability analyses for woven fabric reinforced polymer composites ${ }^{[15-18]}$.

Extensive knowledge has been developed for short/long fibre reinforced thermoplastic composites on the optimization and processing of product performance ${ }^{[19]}$. However, the development of continuous and woven fabric reinforced composites is still not up to the mark. In this study, the novel glass fabric reinforced polypropylene based thermoplastic composite is introduced to help analysis of its formability characteristics under double curvature dome forming. The objective is to investigate the influence of stamp forming process parameters on the formability, using single response and multi-response optimization. Taguchi's L9 orthogonal array (OA) experimental design has been employed in the conduct of forming experimental runs. The significant contribution of each parameter on sheet formability was determined using the analysis of variance. The confirmation test was carried out at optimum parameter levels for the validation of the results of analysis.

\section{Experimentation}

\subsection{Proposed methodology}

The conventionally available manufacturing process for thermoplastic composites is stamp forming, which has proved to be an optimal method for producing products with higher rates. In this study, the stamp forming experiment was conducted on the basis of Taguchi's L9 orthogonal array. Taguchi technique uses a minimum number of experimental trials for finding effective solutions to the problems, by analyzing the entire process parameter space. Taguchi's robust process design was used for solving the single response optimization problems. Grey Relational Analysis (GRA) which is an efficient technique for solving the multi-response problems ${ }^{[20]}$, was implemented. GRA technique uses the grey relational coefficient and grey relational grade for optimizing the multi-response problems. The proposed methodology was analyzed using Minitab-17 software. The analysis identified the proposed multi-response optimization technique offering proof of being an optimal method for providing better formability characteristics during stamp forming of

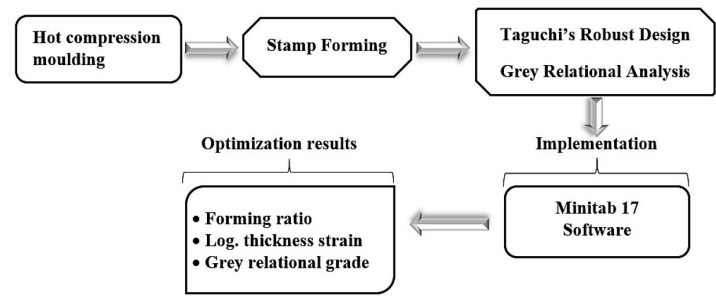

Figure 1. Process flow of the proposed methodology.

thermoplastics. Figure 1 is the process flow chart of the proposed methodology.

\subsection{Selection of materials}

In this experimental work, an isotactic polypropylene $\left(0.5 \mathrm{~mm}\right.$ film, $\left.\rho=0.905 \mathrm{~g} / \mathrm{cm}^{3}\right)$ reinforced with novel plain weave (Figure 2) glass fabric $\left(265 \mathrm{~g} / \mathrm{m}^{2}, \rho=2.54 \mathrm{~g} / \mathrm{cm}^{3}, v_{f}=19 \%\right.$ ) thermoplastic composite fabricated through hot compression molding using film stacking approach was used for the stamp forming process ${ }^{[21]}$. The (3-aminopropyl) trimethoxy silane and polypropylene grafted maleic anhydride ${ }^{[22]}$ were used as the silane coupling agent and matrix compatibilizer, respectively for the purpose of improving the adhesion between the matrix and reinforcement.

The GFRTP laminate was $300 \times 300 \times 2.2 \mathrm{~mm}^{3}$ in size and the novel glass fabrics were stacked in $[0-90]_{4}$ sequence in the laminate. Water jet cutting was used for cutting the $108 \mathrm{~mm}$ diameter circular composite blanks, from the novel plain weave reinforced thermoplastic laminate. This is shown in Figure 3.

\subsection{Stamp forming setup}

Stamp forming setup consists of a stamping die set, an oven which is used for heating the circular blank, a temperature controller unit used to monitor the heating of the steel die and the computer with data acquisition system ${ }^{[23]}$.

The steel die and punch were attached on the $1000 \mathrm{kN}$ Universal Testing Machine (UTM). The punch which had a radius of $27.5 \mathrm{~mm}$ and the die of $30 \mathrm{~mm}$ radius with heating unit were connected to the upper base and lower base of UTM respectively, as shown in Figure 4. The hemispherical punch was used for the application of a uniform load in all directions of the circular blank.

\subsection{Experimental design}

Taguchi's design of experiments approach was implemented for reducing the number of experimental runs and enabling the design of the stamp forming experiments. Three important process parameters such as, Die Temperature (DT), Blank Temperature (BT) and Blank Holder Force (BHF) that could affect the formability behavior of composites, were considered for the investigation ${ }^{[21]}$. Each stamp forming parameter had three distinct levels. These are illustrated in Figure 5. The process parameters were chosen on the basis of findings seen in literatures ${ }^{[7,8,24,25]}$. 


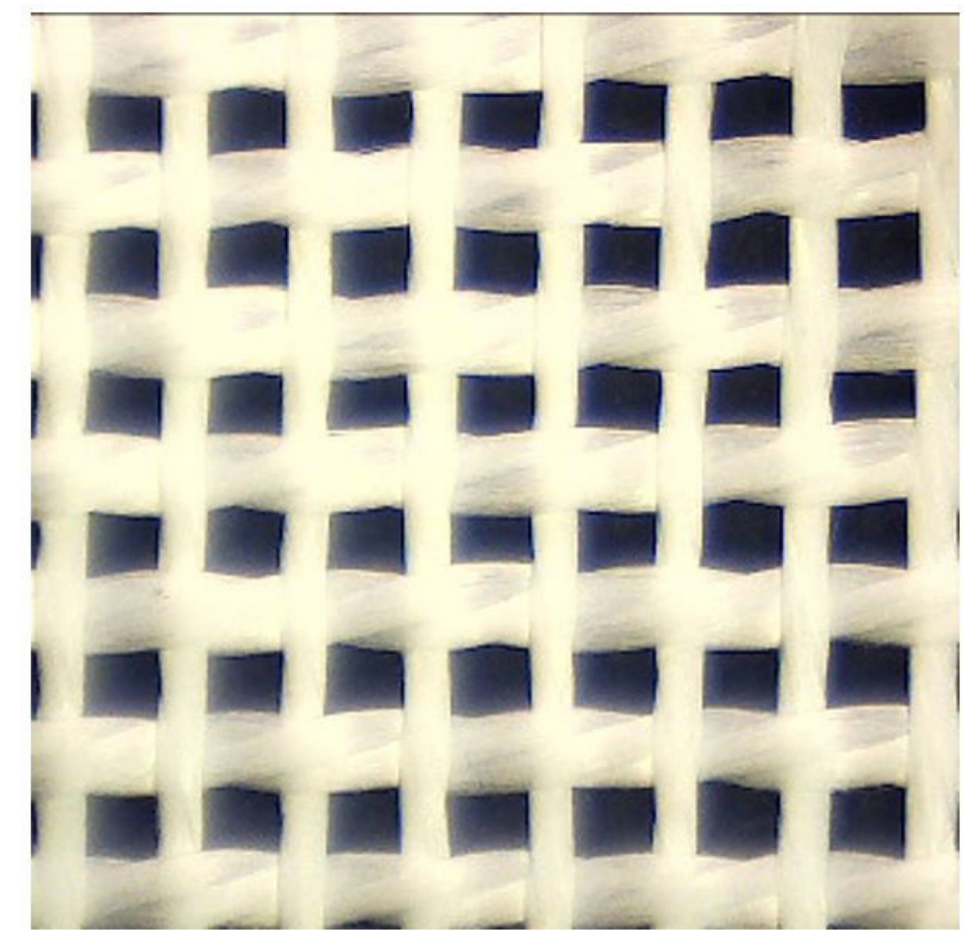

Figure 2. Novel plain weave glass fabric structure.

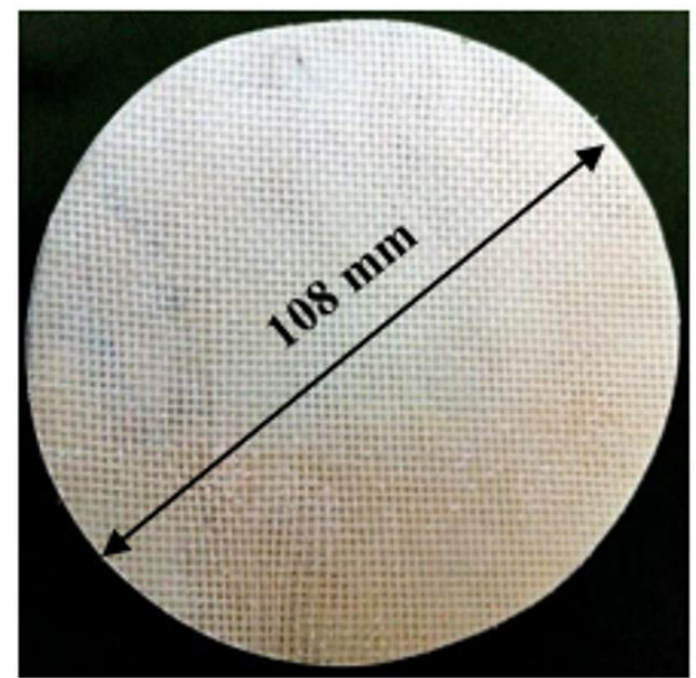

Figure 3. Circular composite blank.

Before taking up the stamp forming process, each circular blank was pre-heated to the definite blank temperature in the oven and then transferred to the steel die. Similarly, before the forming process, the die was heated using four heating rods to the definite temperature. This was monitored using a temperature controller unit. During the stamp forming process, the designed BHF has been acting gradually on the heated blank using four sets of springs. The hemispherical punch moving at the rate of $85 \mathrm{~mm} / \mathrm{min}$, caused deformation of the heated blank into the double curvature die cavity.

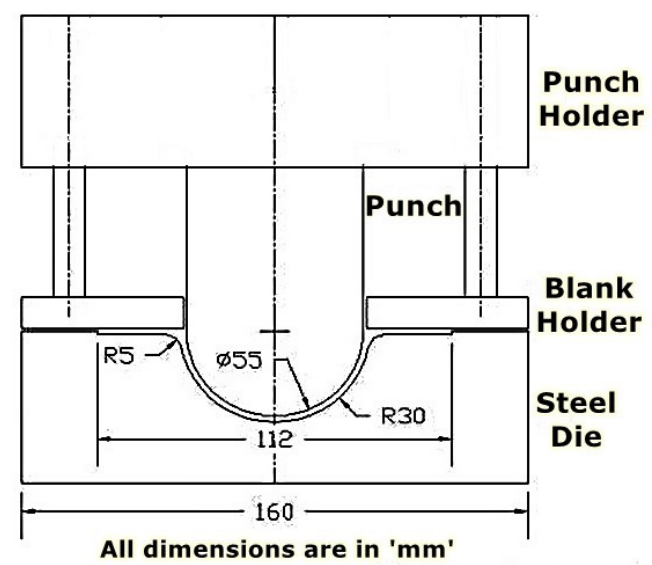

Figure 4. Stamping die set.

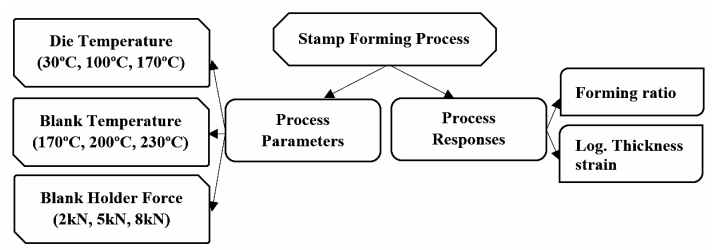

Figure 5. Process parameters and responses.

Following stamp forming, the stamp formed GFRTP component was taken from the steel die for formability analysis. The overall view of the works carried out in the present study is shown in Figure 6. 


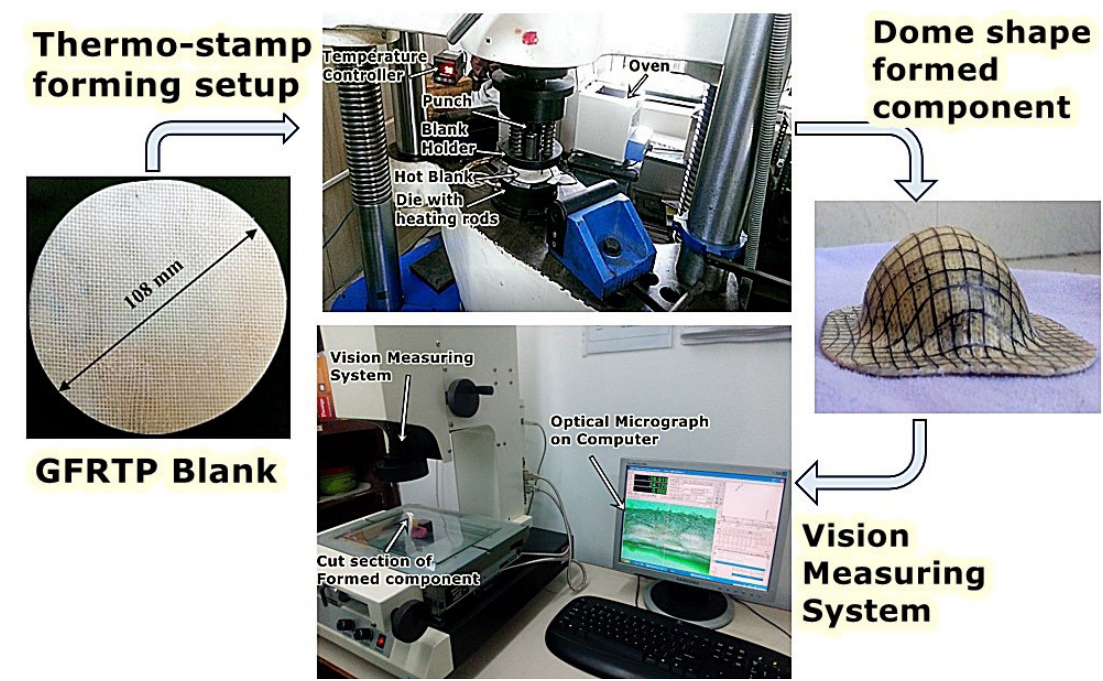

Figure 6. Photographic view of works carried out in the present study.

\section{Results and Discussions}

\subsection{Performance characteristics for formability}

Deformations like in-plane shear, laminate buckling, transverse squeeze flow and matrix degradation that occurred in the blank required analysis for the enhancement of the composite sheet forming process. In this study, significant responses such as forming ratio and thickness strain were considered for the evaluation of the forming behavior of thermoplastic composites.

\subsubsection{Forming Ratio (FR)}

In the case of hemispherical forming, the formability could be determined by considering the maximum extent of possible deformation allowed by the blank. The forming ratio has a significant contribution in the composite sheet forming process $^{[7,26]}$.

$$
\begin{gathered}
\text { For } \min g \text { Ratio }=\frac{\text { Area of Blank }}{\text { Area of formed dome shape }}=\frac{\pi r_{o}^{2}}{2 \pi r_{\text {dome }} h}=\frac{r_{o}^{2}}{2 r_{\text {dome }} h}(1) \\
r_{\text {dome }}=\frac{r_{\text {die }}{ }^{2}+h^{2}}{2 h}
\end{gathered}
$$

Where, $r_{0}$ - Radius of circular blank; $r_{\text {dome }}$ - Radius of dome surface; $r_{d i e}$ - Radius of die opening; $h$ - Height of dome surface.

The draw depth of GFRTP stamp formed component, as illustrated in Figure 7, was measured using a Coordinate measuring machine and was converted into the forming ratio using Equation 1. The radius of dome surface in Equation 1, has been calculated using Equation 2. The draw depth of stamp formed component was considered as the height of the dome surface for the purpose of calculating the forming ratio.

\subsubsection{Logarithmic Thickness Strain (LTS)}

The flange thickness of GFRTP stamp formed component was measured using the Vision measuring system as shown

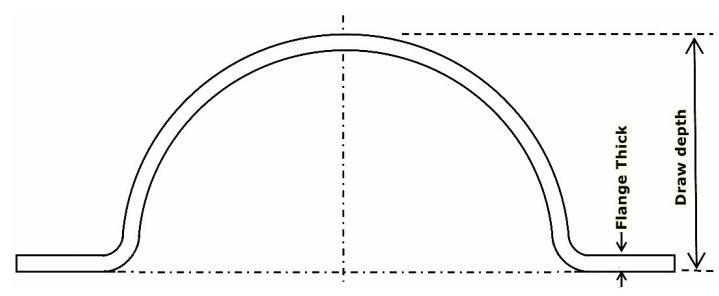

Figure 7. Schematic view of Dome shaped component.

in Figure 6. The logarithmic thickness strain was calculated from the flange thickness for the evaluation of the variations in thickness that occurred in the profile. The calculation was done taking the natural logarithm of the ratio of the flange thickness $(\mathrm{t})$ to the original blank thickness $\left(\mathrm{t}_{\mathrm{o}}\right)$ using Equation $3^{[27]}$.

$$
\text { Logarithmic thickness strain }\left(\varepsilon_{t}\right)=\ln \left(\frac{t}{t_{0}}\right)
$$

The forming experiments were carried out using Taguchi's L9 Orthogonal array. The calculated values of the responses are given in Table 1.

\subsection{Single response optimization}

Optimization of the stamp forming parameters with single objective function was carried out using the Taguchi's robust process design which helps reducing the effects of noise factors by determining the best levels for the control factors. Taguchi has designed three types of signal to noise ratios ( $\mathrm{S} / \mathrm{N}$ ratio), namely, larger-the-better, smaller-the-better and nominal-the-best on the basis of the nature of performance characteristics $^{[28]}$.

In this investigation, a smaller-the-better type $\mathrm{S} / \mathrm{N}$ ratio has been considered for the minimization of the responses, namely, the forming ratio and log. thickness strain (absolute value). The $\mathrm{S} / \mathrm{N}$ ratio for smaller-the-better type is given below. 


$$
\frac{S}{N} \text { ratio }=-10 \log _{10} \frac{1}{r} \sum_{i=1}^{r} \frac{1}{y_{i}^{2}}
$$

Where, $\mathrm{r}=$ number of replications and $\mathrm{y}_{\mathrm{i}}=$ observed response value.

The calculated experimental responses were converted to the $\mathrm{S} / \mathrm{N}$ ratio using Equation 4. The values are presented in Table 1. Regardless of the objective function, a larger $\mathrm{S} / \mathrm{N}$ ratio corresponds to better performance characteristics. The average $\mathrm{S} / \mathrm{N}$ ratio values of the forming ratio and the log. thickness strain for all the levels were calculated and are tabulated in Table 2. Based on the larger S/N ratio values, the optimal level setting was predicted as $\mathrm{DT}_{3} \mathrm{BT}_{1} \mathrm{BHF}_{1}$ and $\mathrm{DT}_{2} \mathrm{BT}_{3} \mathrm{BHF}_{3}$ for the forming ratio and log. thickness strain, respectively. The die temperature, blank temperature and the blank holder force were set at $170^{\circ} \mathrm{C}, 170^{\circ} \mathrm{C}$, and $2 \mathrm{kN}$ respectively for the forming ratio; while the forming parameters were set at $100^{\circ} \mathrm{C}, 230^{\circ} \mathrm{C}$, and $8 \mathrm{kN}$ respectively for the log. thickness strain.

\subsubsection{Analysis of variance}

The purpose of analysis of variance (ANOVA) is to identify the most significant factor which would affect the performance characteristics. F-test was carried out for understanding the significance of the process parameters. The factor with high F-value is greatly significant in the effect on the response of the process. The effects of forming parameters, namely, die temperature, blank temperature and blank holder force on the responses were analyzed using Minitab-17 software. The ANOVA details of the forming ratio and the log. thickness strain, were calculated and are presented in Table 3. The contribution of each parameter indicates the degree of influence of that parameter on the formability characteristics and is highlighted in Table 3. The analysis shows clearly the die temperature as the most

Table 1. Taguchi's L9 OA with process parameters, responses and $\mathrm{S} / \mathrm{N}$ ratio.

\begin{tabular}{ccccccccc}
\hline & \multicolumn{3}{c}{ Process parameters } & \multicolumn{2}{c}{ Process responses } & \multicolumn{3}{c}{ S/N ratio } \\
\cline { 2 - 9 } Exp. runs & Die Temp. $\left({ }^{\circ} \mathbf{C}\right)$ & $\begin{array}{c}\text { Blank Temp. } \\
\left({ }^{\circ} \mathbf{C}\right)\end{array}$ & $\begin{array}{c}\text { Blank Holder } \\
\text { Force } \\
(\mathbf{k N})\end{array}$ & FR & LTS & FR & LTS \\
\hline 1 & 30 & 170 & 2 & 1.79 & 0.079 & -5.057 & 22.087 \\
2 & 30 & 200 & 5 & 1.85 & 0.167 & -5.343 & 15.543 \\
3 & 30 & 230 & 8 & 1.82 & 0.036 & -5.201 & 28.942 \\
4 & 100 & 170 & 5 & 1.76 & 0.108 & -4.910 & 19.361 \\
5 & 100 & 200 & 8 & 1.73 & -0.047 & -4.761 & 26.647 \\
6 & 100 & 230 & 2 & 1.72 & 0.070 & -4.711 & 23.073 \\
7 & 170 & 170 & 8 & 1.67 & -0.229 & -4.454 & 12.809 \\
8 & 170 & 200 & 2 & 1.66 & -0.116 & -4.402 & 18.747 \\
9 & 170 & 230 & 5 & 1.71 & -0.157 & -4.660 & 16.072 \\
\hline
\end{tabular}

FR - Forming Ratio, LTS - Logarithmic Thickness Strain.

Table 2. Response table for forming ratio and log. Thickness strain.

\begin{tabular}{|c|c|c|c|c|c|c|}
\hline \multirow{2}{*}{$\begin{array}{c}\text { Process } \\
\text { Parameter }\end{array}$} & \multicolumn{3}{|c|}{ Forming ratio } & \multicolumn{3}{|c|}{ Log. thickness strain } \\
\hline & DT & BT & BHF & DT & BT & BHF \\
\hline Level 1 & -5.20 & -4.81 & -4.72 & 22.19 & 18.09 & 21.30 \\
\hline Level 2 & -4.79 & -4.84 & -4.97 & 23.03 & 20.31 & 16.99 \\
\hline Level 3 & -4.51 & -4.86 & -4.81 & 15.88 & 22.70 & 22.80 \\
\hline Delta & 0.70 & 0.05 & 0.25 & 7.15 & 4.61 & 5.81 \\
\hline Rank & 1 & 3 & 2 & 1 & 3 & 2 \\
\hline Settings & \multicolumn{3}{|c|}{$\mathrm{DT}_{3} \mathrm{BT}_{1} \mathrm{BHF}_{1}$} & \multicolumn{3}{|c|}{$\mathrm{DT}_{2} \mathrm{BT}_{3} \mathrm{BHF}_{3}$} \\
\hline
\end{tabular}

DT - Die Temperature, BT - Blank Temperature, BHF - Blank Holder Force.

Table 3. Analysis of variance for forming ratio and log. Thickness strain.

\begin{tabular}{cccccccccc}
\hline & & \multicolumn{4}{c}{ Forming ratio } & \multicolumn{3}{c}{ Log. thickness strain } \\
\cline { 3 - 8 } Factor & DoF & SS & MSS & $\begin{array}{c}\text { F } \\
\text { ratio }\end{array}$ & $\begin{array}{c}\text { Contribution } \\
\mathbf{( \% )}\end{array}$ & SS & MSS & $\begin{array}{c}\text { F } \\
\text { ratio }\end{array}$ & $\begin{array}{c}\text { Contribution } \\
\text { (\%) }\end{array}$ \\
\hline DT & 2 & 0.73189 & 0.3659 & 2930 & 88.01 & 91.71 & 45.85 & 1.93 & 40.63 \\
BT & 2 & 0.00378 & 0.0019 & 15 & 0.46 & 31.89 & 15.94 & 0.67 & 14.13 \\
BHF & 2 & 0.09568 & 0.0478 & 383 & 11.51 & 54.55 & 27.27 & 1.15 & 24.17 \\
Error & 2 & 0.00025 & 0.0001 & & 0.03 & 47.58 & 23.79 & & 21.08 \\
Total & 8 & 0.83161 & & & 100 & 225.73 & & & 100 \\
\hline
\end{tabular}

DoF - Degrees of Freedom, SS - Sum of Squares, MSS - Mean Sum of Squares, DT - Die Temperature, BT - Blank Temperature, BHF - Blank Holder Force. 
significant factor affecting the performance characteristics of the dome-shape formed components followed by the blank holder force and blank temperature for both the responses. However, considerable variations on the percentage contribution of each parameter were noticed between the responses. This is highlighted in Table 3.

\subsection{Multi-response optimization}

The multi-response optimization problem could be transformed into a single response optimization problem with the grey relational grade as the objective function ${ }^{[29]}$, using grey relational analysis. The $\mathrm{S} / \mathrm{N}$ ratio values of the forming ratio and log. thickness strain of the stamp formed components, presented in Table 1, were analyzed for a study of the effects of the stamp forming parameters. Normalization is a transformation done on a single input data for the even distribution of data and scaling it into an acceptable range. The $\mathrm{S} / \mathrm{N}$ ratio values of the responses require normalization from zero to one for the purpose of optimizing the stamp forming process. The process of normalizing the responses is known as the grey relational generation, wherein both the responses (i.e.) forming ratio and log. thickness strain, should follow the smaller-the-better type problem that could be expressed as in Equation 5.

$$
x_{i}(k)=\frac{\max y_{i}(k)-y_{i}(k)}{\max y_{i}(k)-\min y_{i}(k)}
$$

Where, $x_{i}(k)$ is the grey relational generation, $\max y_{i}(k)$ is the highest value of $y_{i}(k)$ for the $\mathrm{k}^{\text {th }}$ response and min $y_{i}(k)$ is the lowest value of $y_{i}(k)$ for the $\mathrm{k}^{\text {th }}$ response.

Using Equation 5, the $\mathrm{S} / \mathrm{N}$ ratio of the responses were normalized. Details are presented in Table 4. Grey relational coefficient (GRC) $\xi_{i}(k)$ was calculated on the basis of the normalized values for showing the relationship between the desired and the actual experimental values, using Equation 6 . An ideal sequence for the responses is $x_{0}(k)$ at $(k=1,2, .$.$) .$

$$
\xi_{i}(k)=\frac{\Delta_{\min }+\varsigma \Delta_{\max }}{\Delta_{o i(K)}+\varsigma \Delta_{\max }}
$$

Where, $\Delta_{0 i}(k)=\| x_{0}(k)-x_{i}(k)$ the real value of the difference between $x_{0}(k)$ and $x_{i}(k), \varsigma$ is distinguishing coefficient $\left(0 \_1\right)$; $\Delta_{\min }$ smallest value of $\Delta_{o i}$; and $\Delta_{\max }$ largest value of $\Delta_{o i}$.

Using Equation $7^{[30]}$, the weighted grey relational grade $(g)$ was calculated from the grey relational coefficients of the selected responses.

$$
g_{i}=\sum_{k=1}^{n} w_{i}(k) \xi_{i}(k)
$$

Where, $\mathrm{n}$ - number of responses, $w$ - weight of the $\mathrm{k}^{\text {th }}$ response.

As stated in the Literatures ${ }^{[30,31]}$, the weights were assigned on the basis of the engineering or decision makers' judgments. However, in a real case, it is still very difficult to define a particular weight for each of the responses. Hence, the weights are assigned on the basis of the significance of the responses ${ }^{[32]}$. In this investigation of composite sheet forming, the significance of the forming ratio response was seen as much higher than that of the log. thickness strain response. Henceforth, the weights for the responses were assigned as given in Table $4^{[28,33]}$. The grey relational coefficients of forming ratio and log. thickness strain and the weighted grey relational grades for the four cases were calculated and have been tabulated in Table 4 .

\subsubsection{Optimum level of factors}

Maximization of weighted grade leads to the better product quality. Hence, the effect of factor was estimated on the basis of the weighted grade. The average grey relational grade was calculated for each level of factors in the four cases. Details are presented in Table 5, along with the optimum level of factors. The optimal forming parameters setting was predicted from the highest grey relational grade of the levels ${ }^{[29,34]}$. The response table (Table 5) shows the predicted optimal level setting for all four cases as $\mathrm{DT}_{3} \mathrm{BT}_{2} \mathrm{BHF}_{1}$ The die temperature, blank temperature and the blank holder force were set at $170^{\circ} \mathrm{C}, 200^{\circ} \mathrm{C}$, and $2 \mathrm{kN}$ respectively.

\subsubsection{Analysis of variance}

The ANOVA details of weighted grey relational grade for the four cases are presented in Tables 6 and 7. The analysis clearly shows the die temperature as the most significant factor ${ }^{[8]}$ followed by the blank holder force and blank temperature for all the four cases, in affecting

\begin{tabular}{|c|c|c|c|c|c|c|c|c|}
\hline \multirow[b]{2}{*}{ Exp. Runs } & \multicolumn{2}{|c|}{ Normalized Values } & \multicolumn{2}{|c|}{ Grey Relational Coefficient } & \multicolumn{4}{|c|}{ Weighted Grey Relational Grades } \\
\hline & FR & LTS & FR & LTS & $\begin{array}{c}0.6 \times \text { FR }+ \\
0.4 \times \text { LTS }\end{array}$ & $\begin{array}{c}0.7 \times \text { FR }+ \\
0.3 \times \text { LTS }\end{array}$ & $\begin{array}{c}0.8 \times \text { FR }+ \\
0.2 \times \text { LTS }\end{array}$ & $\begin{array}{c}0.9 \times \text { FR + } \\
0.1 \times \text { LTS }\end{array}$ \\
\hline 1 & 0.288 & 0.778 & 0.413 & 0.692 & 0.528 & 0.500 & 0.473 & 0.446 \\
\hline 2 & 0.000 & 0.320 & 0.333 & 0.424 & 0.369 & 0.360 & 0.351 & 0.342 \\
\hline 3 & 0.095 & 1.000 & 0.356 & 1.000 & 0.622 & 0.559 & 0.496 & 0.434 \\
\hline 4 & 0.486 & 0.628 & 0.493 & 0.573 & 0.518 & 0.509 & 0.499 & 0.490 \\
\hline 5 & 0.637 & 0.944 & 0.579 & 0.899 & 0.700 & 0.667 & 0.634 & 0.601 \\
\hline 6 & 0.688 & 0.607 & 0.616 & 0.560 & 0.657 & 0.644 & 0.631 & 0.617 \\
\hline 7 & 0.947 & 0.000 & 0.904 & 0.333 & 0.673 & 0.730 & 0.787 & 0.844 \\
\hline 8 & 1.000 & 0.587 & 1.000 & 0.548 & 0.819 & 0.864 & 0.910 & 0.955 \\
\hline 9 & 0.739 & 0.371 & 0.657 & 0.443 & 0.565 & 0.585 & 0.605 & 0.626 \\
\hline
\end{tabular}
the performance characteristics of dome-shape formed

Table 4. Normalized values, grey relational coefficients and weighted grades of the responses.

FR - Forming Ratio, LTS - Logarithmic Thickness Strain. 
Table 5. Response table for weighted grey relational grades (Cases: 1 to 4$)$.

\begin{tabular}{|c|c|c|c|c|c|c|c|c|c|c|c|c|}
\hline \multirow{2}{*}{$\begin{array}{c}\text { Cases } \\
\text { Process } \\
\text { Parameter }\end{array}$} & \multicolumn{3}{|c|}{$(0.6 \times$ FR $)+(0.4 \times$ LTS $)$} & \multicolumn{3}{|c|}{$(0.7 \times$ FR $)+(0.3 \times$ LTS $)$} & \multicolumn{3}{|c|}{$(0.8 \times$ FR $)+(0.2 \times$ LTS $)$} & \multicolumn{3}{|c|}{$(0.9 \times$ FR $)+(0.1 \times$ LTS $)$} \\
\hline & DT & BT & BHF & DT & BT & BHF & DT & BT & BHF & DT & BT & BHF \\
\hline Level 1 & 0.507 & 0.573 & 0.668 & 0.473 & 0.580 & 0.670 & 0.440 & 0.586 & 0.671 & 0.407 & 0.593 & 0.673 \\
\hline Level 2 & 0.625 & 0.630 & 0.484 & 0.607 & 0.631 & 0.485 & 0.588 & 0.632 & 0.485 & 0.569 & 0.633 & 0.486 \\
\hline Level 3 & 0.686 & 0.615 & 0.665 & 0.727 & 0.596 & 0.652 & 0.767 & 0.578 & 0.639 & 0.808 & 0.559 & 0.626 \\
\hline Delta & 0.179 & 0.057 & 0.184 & 0.253 & 0.051 & 0.185 & 0.327 & 0.054 & 0.186 & 0.401 & 0.074 & 0.186 \\
\hline Rank & 1 & 3 & 2 & 1 & 3 & 2 & 1 & 3 & 2 & 1 & 3 & 2 \\
\hline Settings & \multicolumn{3}{|c|}{$\mathrm{DT}_{3} \mathrm{BT}_{2} \mathrm{BHF}_{1}$} & \multicolumn{3}{|c|}{$\mathrm{DT}_{3} \mathrm{BT}_{2} \mathrm{BHF}_{1}$} & \multicolumn{3}{|c|}{$\mathrm{DT}_{3} \mathrm{BT}_{2} \mathrm{BHF}_{1}$} & \multicolumn{3}{|c|}{$\mathrm{DT}_{3} \mathrm{BT}_{2} \mathrm{BHF}_{1}$} \\
\hline
\end{tabular}

DT - Die Temperature, BT - Blank Temperature, BHF - Blank Holder Force, FR - Forming Ratio, LTS - Logarithmic Thickness Strain.

Table 6. Analysis of variance for weighted grey relational grades (Cases: 1 and 2).

\begin{tabular}{|c|c|c|c|c|c|c|c|c|c|}
\hline \multicolumn{2}{|c|}{ Cases: 1 and 2} & \multicolumn{4}{|c|}{$(0.6 \times$ FR $)+(0.4 \times$ LTS $)$} & \multicolumn{4}{|c|}{$(0.7 \times$ FR $)+(0.3 \times$ LTS $)$} \\
\hline Factor & DoF & SS & MSS & F-ratio & Contribution (\%) & SS & MSS & F-ratio & Contribution (\%) \\
\hline DT & 2 & 0.04985 & 0.0249 & 4.34 & 37.42 & 0.09618 & 0.0481 & 12.07 & 56.35 \\
\hline BT & 2 & 0.00516 & 0.0026 & 0.45 & 3.88 & 0.00404 & 0.0020 & 0.51 & 2.37 \\
\hline BHF & 2 & 0.06673 & 0.0334 & 5.81 & 50.09 & 0.06251 & 0.0313 & 7.85 & 36.62 \\
\hline Error & 2 & 0.01148 & 0.0057 & & 8.62 & 0.00797 & 0.0040 & & 4.67 \\
\hline Total & 8 & 0.13323 & & & 100 & 0.17069 & & & 100 \\
\hline
\end{tabular}

DoF - Degrees of Freedom, SS - Sum of Squares, MSS - Mean Sum of Squares, DT - Die Temperature, BT - Blank Temperature, BHF - Blank Holder Force, FR - Forming Ratio, LTS - Logarithmic Thickness Strain.

Table 7. Analysis of variance for weighted grey relational grades (Cases: 3 and 4).

\begin{tabular}{|c|c|c|c|c|c|c|c|c|c|}
\hline \multicolumn{2}{|c|}{ Cases: 3 and 4} & \multicolumn{4}{|c|}{$(0.8 \times$ FR $)+(0.2 \times$ LTS $)$} & \multicolumn{4}{|c|}{$(0.9 \times$ FR $)+(0.1 \times$ LTS $)$} \\
\hline Factor & DoF & SS & MSS & F-ratio & Contribution (\%) & SS & MSS & F-ratio & Contribution (\%) \\
\hline DT & 2 & 0.16088 & 0.0804 & 24.51 & 69.47 & 0.24397 & 0.1220 & 33.53 & 77.23 \\
\hline BT & 2 & 0.00504 & 0.0025 & 0.77 & 2.18 & 0.00816 & 0.0041 & 1.12 & 2.58 \\
\hline BHF & 2 & 0.05910 & 0.0295 & 9.00 & 25.52 & 0.05650 & 0.0283 & 7.77 & 17.89 \\
\hline Error & 2 & 0.00656 & 0.0033 & & 2.83 & 0.00728 & 0.0036 & & 2.30 \\
\hline Total & 8 & 0.23158 & & & 100 & 0.31590 & & & 100 \\
\hline
\end{tabular}

DoF - Degrees of Freedom, SS - Sum of Squares, MSS - Mean Sum of Squares, DT - Die Temperature, BT - Blank Temperature, BHF - Blank Holder Force, FR - Forming Ratio, LTS - Logarithmic Thickness Strain.

components. With increase in the weightage of forming ratio, the contribution of die temperature increased from $37.5 \%$ to $77.2 \%$, whereas the contribution of blank holder force and blank temperature decreased from $50 \%$ to $17.9 \%$ and from $3.9 \%$ to $2.2 \%$ respectively.

\subsection{Predicted optimum condition}

The optimum level of factors obtained on the basis of experiments was $\mathrm{DT}_{3} \mathrm{BT}_{2} \mathrm{BHF}_{1}$ for all the four cases of multi-response optimization. The grey relational grade was predicted for all the cases using Equation $8^{[34]}$. The average grey relational grade values of the factors at their optimum levels are taken from Table 5, in order to calculate the predicted grade value. The overall average grey relational grade $(\mathrm{T})$ was calculated by averaging the grey relational grades of all the factors.

Grey Relational Grade $($ predicted $)=D T_{3}+B T_{2}+B H F_{1}-2 T$

\subsubsection{Confirmation run}

The confirmation experiment was performed by setting the forming parameters at the optimum levels. The die temperature, the blank temperature and the blank holder force were set at $170^{\circ} \mathrm{C}, 200^{\circ} \mathrm{C}$ and $2 \mathrm{kN}$ respectively for all the four cases. The results are presented in the Table 8 . The predicted and confirmation experiment run values of the grey relational grade for the four cases of multi-response optimization problems are listed in Table 8 along with the draw depth and flange thickness of the stamp formed components. As with multi-response optimization, the confirmation experiment was conducted for single response optimization problems and the details are presented in Table 8.

The confidence interval (C.I.) and effective sample size were calculated using Equations 9 and $10^{[35]}$.

$$
\text { C.I. }=\sqrt{\frac{M S S_{\text {error }}}{n_{\text {eff }}} F_{\alpha(1, \text { df of error })}}
$$

Where, $F_{\alpha(1, \text { df of error })}$ is table F-value at given significance level, $M S S_{\text {ERROR }}$ is mean sum of squares of error, $\mathrm{n}_{\text {eff }}$ is effective sample size

$$
n_{\text {eff }}=\frac{\text { Total number of experimental runs }}{(1+\text { Total DoF associated } \text { with items used in }}=1.286
$$

Details of the $90 \%$ confidence interval of the predicted grade values are presented in Table 8 . The experimental grade values of the multi-response optimization problems were seen lying well within the confidence interval of the corresponding predicted values, showing the good matching of the predicted grey relational grades with the experimental 
Table 8. Grey relational grade values of predicted and experimental runs.

\begin{tabular}{|c|c|c|c|c|c|c|}
\hline & Optimum setting & $\begin{array}{c}\text { Predicted } \\
\text { grade }\end{array}$ & $\begin{array}{c}\text { Experimental } \\
\text { grade }\end{array}$ & $\begin{array}{c}\text { Confidence } \\
\text { Interval }\end{array}$ & $\begin{array}{c}\text { Draw depth } \\
(\mathrm{mm})\end{array}$ & $\begin{array}{c}\text { Flange thickness } \\
(\mathrm{mm})\end{array}$ \\
\hline Case 1 & $\mathrm{DT}_{3} \mathrm{BT}_{2} \mathrm{BHF}_{1}$ & 0.772 & 0.819 & 0.578 to 0.966 & 29.25 & 1.96 \\
\hline Case 2 & $\mathrm{DT}_{3} \mathrm{BT}_{2} \mathrm{BHF}_{1}$ & 0.822 & 0.864 & 0.659 to 0.985 & 29.25 & 1.96 \\
\hline Case 3 & $\mathrm{DT}_{3} \mathrm{BT}_{2} \mathrm{BHF}_{1}$ & 0.873 & 0.910 & 0.725 to 1.021 & 29.25 & 1.96 \\
\hline Case 4 & $\mathrm{DT}_{3} \mathrm{BT}_{2} \mathrm{BHF}_{1}$ & 0.923 & 0.955 & 0.768 to 1.078 & 29.25 & 1.96 \\
\hline FR & $\mathrm{DT}_{3} \mathrm{BT}_{1} \mathrm{BHF}_{1}$ & -4.40 & -4.91 & -4.43 to -4.37 & 28.89 & 1.98 \\
\hline LTS & $\mathrm{DT}_{2} \mathrm{BT}_{3} \mathrm{BHF}_{3}$ & 16.76 & 27.04 & 4.20 to 29.32 & 27.50 & 2.30 \\
\hline
\end{tabular}

FR - Forming Ratio, LTS - Logarithmic Thickness Strain.

grey relational grades for the optimum process parameter setting. For the forming ratio, the experimental value was not seen lying within the C.I. of predicted values. Similarly, for log. thickness strain, the range of C.I. was very huge due to a high $\%$ error in the ANOVA results. Hence, the optimal settings of single response optimization problems did not provide the desired values.

\subsubsection{Comparison between single and multi-response optimization}

In the case of the single response optimization, the optimal forming parameters setting were $170^{\circ} \mathrm{C}, 170^{\circ} \mathrm{C}$, and $2 \mathrm{kN}$ respectively for the forming ratio and $100^{\circ} \mathrm{C}, 230^{\circ} \mathrm{C}$, and $8 \mathrm{kN}$ respectively for the log. thickness strain. In the case of multi-response optimization, the optimal forming parameters setting were $170^{\circ} \mathrm{C}, 200^{\circ} \mathrm{C}$, and $2 \mathrm{kN}$ respectively for all the four cases.

The draw depth $(29.25 \mathrm{~mm})$ and flange thickness $(1.96 \mathrm{~mm})$ of the stamp formed component obtained at the multi-response optimization problems were found to be better than the corresponding values of the single response optimization problems. The conclusion from the study is that the stamp formed components obtained have better performance characteristics in the multi-response optimization, instead of in a single response optimization.

\subsection{Effects of process parameters on forming ratio}

The measured draw depth was transformed into meaningful performance characteristic such as the forming ratio for effective assessment of the forming behavior. The typical forming ratio for the maximum draw depth formed component was 1.62. This was obtained by considering the height of dome surface as equal to the radius of the die. Figure 8 is the plotting of the forming ratio of GFRTP components under various experimental runs. It reveals the achievement of the forming ratio closer to that of the typical value of 1.62 for the experimental runs no. 7 to no.9. This observation indicates the components formed under high die temperature process conditions as attained the larger draw depth, closely approaching the typical forming ratio. This could be due to the reduced flow resistance for the blank as a result of low temperature difference between the heated blank and hot die.

The blanks formed under low BHF (experimental runs no. 1, no. 6 and no.8) achieved a reasonably good forming ratio but exhibited wrinkling around the flange and buckling in the dome bend area as shown in Figures 9 and $10^{[24]}$. The increase in rate of flow of the blank from the outer region of flange developed a severe strain on the blank elements due to the high circumferential compressive stress, which led to the formation of wrinkling at low BHF. However, the increase

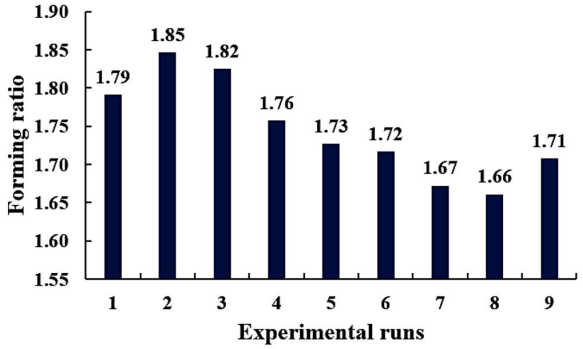

Figure 8. Forming ratio of components for the various experimental runs.

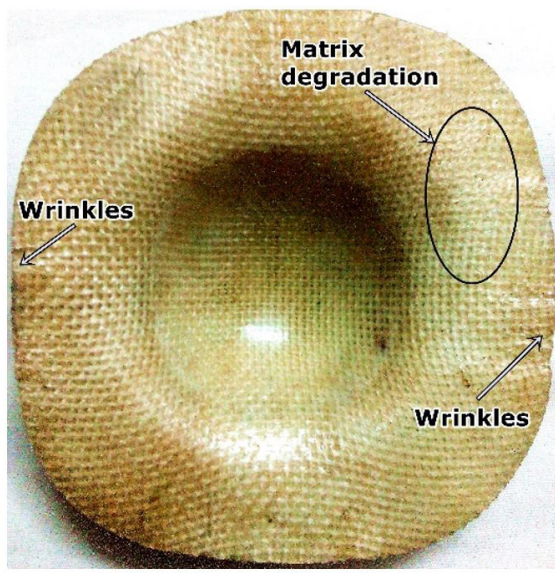

Figure 9. Wrinkles in GFRTP components.

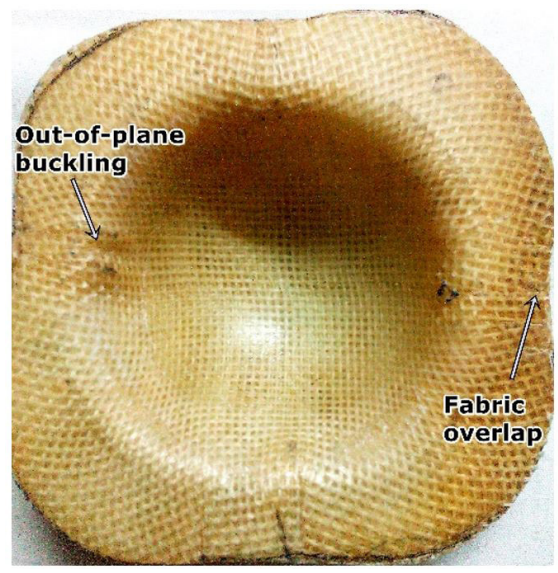

Figure 10. Buckling \& Overlap in GFRTP components. 
in BHF caused a big reduction in the prevalence of defects, but with a slight reduction in the forming ratio. The increased flow resistance at high BHF simultaneously increased the radial tensile stress on the blank, which in turn regulated the flow of blank by controlling the circumferential stress and also minimized the occurrence of wrinkling.

The increase in blank temperature caused a significant reduction in the resin viscosity with simultaneous enhancement of the fluidity of the resin. However, the further increase in blank temperature led to the sticking of matrix resin on the punch and die surfaces which caused diminution in the surface quality of the components formed. The blanks formed under high blank temperature (experimental runs no.3, no. 6 and no.9) were subjected to severe degradation as a result of the oxidation of matrix.

\subsection{Effects of process parameters on logarithmic thickness strain}

The logarithmic thickness strain was used for the estimation of the amount of thinning and thickening that occurred on the flange portion of the stamp formed components. The logarithmic thickness strain of GFRTP stamp formed components under various experimental runs has been plotted (Figure 11). Compared to the initial blank thickness, the components formed under high die temperature conditions were up to $22 \%$ thinner, whereas the low die temperature formed components were up to $16 \%$ thicker at the flange portion $^{[8]}$. The reason is that the high temperature difference between the heated blank and die, made the blank to solidify

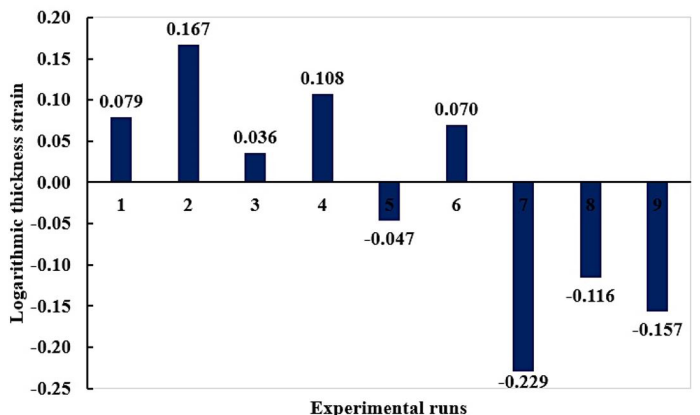

Figure 11. Logarithmic thickness strain for the experimental runs.

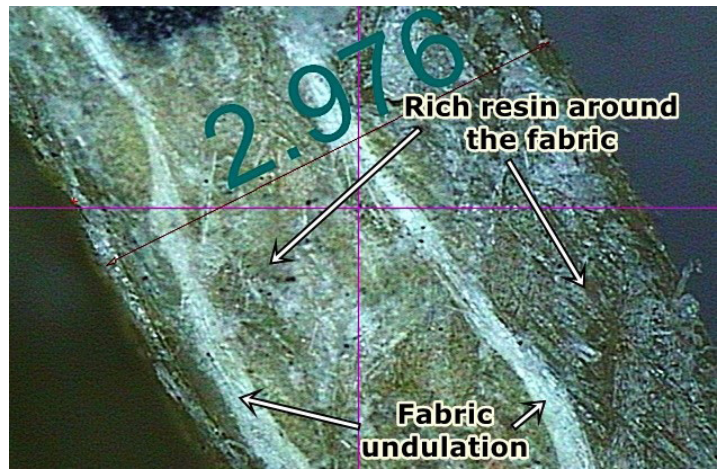

Figure 12. Microscopic image of the specimen at the flange. at the faster rate and led to the formation of a severe wrinkling on the surface of components, which in turn increased the flange thickness.

Fibre buckling was observed when the blank holder force acting on the blank fell below the circumferential compressive stress as shown in the microscopic image (Figure 12) of the specimen, at the flange portion. This in turn caused an increase in the flange thickness ${ }^{[25]}$. As elaborately discussed in the previous section, the components formed under low BHF showed a relatively high wrinkling than the high BHF components, as a result of high circumferential stress on the blank elements. The conclusion from the experimental results is that the flange thickness depends on the amount of temperature difference as well as the frictional force between the heated blank and the die.

\section{Conclusion}

The focus of this experimental investigation was the influence of stamp forming parameters on the formability of thermoplastic composite using Taguchi based grey relational analysis for single and multi-response optimization problems. The following conclusions are drawn:

- The analysis helped the identification of die temperature acting as a prominent factor, followed by the blank holder force and blank temperature in controlling the performance characteristics of stamp formed components for both single and multi-response optimization problems;

- Compared to single response optimization, Taguchi based multi-response optimization is found to be a very powerful tool for predicting the performance characteristics in the stamp forming of GFRTP composite;

- The conclusion from the grey relational analysis is that the stamp formed components could be obtained with better performance characteristics at the die temperature of $170^{\circ} \mathrm{C}$, blank temperature of $200^{\circ} \mathrm{C}$ and blank holder force of $2 \mathrm{kN}$ process condition;

- Stamp forming process produced the hemispherical components with the maximum draw depth of $29.25 \mathrm{~mm}$ and flange thickness of $1.96 \mathrm{~mm}$, without much wrinkling and defects;

- Confirmation test results helped the verification of optimum process parameter levels determined and the experimental grade obtained lies well within the confidence interval of the predicted value;

- The increase in die temperature resulted the improvement in the forming ratio by reducing the flow resistance between the heated blank and die, but a decrease in the flange thickness of the components;

- The increase in blank holder force caused a slight reduction in the forming ratio and the flange thickness but improved the quality of the profile obtained;

- The change in blank temperature has been identified as having an insignificant effect on the performance characteristics. 


\section{Acknowledgements}

The authors wish to thank Anna University and Velammal Engineering College, Chennai for the help rendered in preparing the laminates and conducting the stamp forming experiments.

\section{References}

1. Hufenbach, W., Böhm, R., Thieme, M., Winkler, A., Mäder, E., Rausch, J., \& Schade, M. (2011). Polypropylene/glass fibre 3D-textile reinforced composites for automotive applications. Materials \& Design, 32(3), 1468-1476. http://dx.doi.org/10.1016/j. matdes.2010.08.049.

2. Spadetti, C., Silva, E. A. D., Fo., Sena, G. L. D., \& Melo, C. V. P. D. (2017). Thermal and mechanical properties of postconsumer polypropylene composites reinforced with cellulose fibers. Polímeros: Ciência e Tecnologia, 27(Special), 84-90. http://dx.doi.org/10.1590/0104-1428.2320.

3. Rietman, B., Niazi, M. S., \& Akkerman, R. (2013). FibreChain characterization and modeling of thermoplastic composites processing. In Proceedings of the Texcomp-11 Conference ( $\mathrm{p}$. 1-7). Leuven, Belgie: S. V. Lomov.

4. Yanagimoto, J., \& Ikeuchi, K. (2012). Sheet forming process of carbon fiber reinforced plastics for lightweight parts. CIRP Annals-Manufacturing Technology, 61(1), 247-250. http:// dx.doi.org/10.1016/j.cirp.2012.03.129.

5. Mehat, N. M., Kamaruddin, S., \& Othman, A. R. (2014) Hybrid integration of taguchi parametric design, grey relational analysis, and principal component analysis optimization for plastic gear production. Chinese Journal of Engineering, 351206. http://dx.doi.org/10.1155/2014/351206.

6. Davey, S., Cantwell, W., Das, R., \& Kalyanasundaram, S. (2012). Investigation into the formability of carbon fibre/polyether ether ketone composite sheets in stamp forming processes. In Proceedings of the 15th European Conference on Composite Materials (p. 1-8). Venice, Italy: ECCM. Retrieved in 2017, November 28, from http://www.escm.eu.org/eccm15/data/ assets/666.pdf

7. Nurul Fazita, M. R., Jayaraman, K., \& Bhattacharyya, D (2016). Formability analysis of bamboo fabric reinforced poly (Lactic) acid composites. Materials (Basel), 9(7), 539. http:// dx.doi.org/10.3390/ma9070539. PMid:28773662.

8. Lessard, H., Lebrun, G., Benkaddour, A., \& Pham, X. T. (2015) Influence of process parameters on the thermostamping of a $[0 / 90]_{12}$ carbon/polyether ether ketone laminate. Composites. Part A, Applied Science and Manufacturing, 70, 59-68. http:// dx.doi.org/10.1016/j.compositesa.2014.12.009.

9. Ma, C. M., Yu, C. T., \& Cheng, B. W. (2014). Optimization of stamp forming process for thermoplastic composites. Research Journal of Applied Sciences, Engineering and Technology, 7(8), 1568-1572. http://dx.doi.org/10.19026/rjaset.7.433.

10. Zhu, B., Yu, T. X., Zhang, H., \& Tao, X. M. (2011). Experimental investigation of formability of commingled woven composite preform in stamping operation. Composites. Part B, Engineering, 42(2), 289-295. http://dx.doi.org/10.1016/j. compositesb.2010.05.006.

11. Venkatesan, S., \& Kalyanasundaram, S. (2010). Finite element analysis and optimization of process parameters during stamp forming of composite materials. IOP Conference Series. Materials Science and Engineering, 10(1), 012138. http:// dx.doi.org/10.1088/1757-899X/10/1/012138.

12. Kalyanasundaram, S., Dharmalingam, S., Venkatesan, S., \& Sexton, A. (2013). Effect of process parameters during forming of self reinforced-PP based Fiber Metal Laminate.
Composite Structures, 97, 332-337. http://dx.doi.org/10.1016/j. compstruct.2012.08.053.

13. Vanclooster, K., Van Goidsenhoven, S., Lomov, S. V., \& Verpoest, I. (2009). Optimizing the deep drawing of multilayered woven fabric composites. International Journal of Material Forming, 2(1), 153-156. http://dx.doi.org/10.1007/ s12289-009-0522-9.

14. Lee, J. S., Hong, S. J., Yu, W. R., \& Kang, T. J. (2007). The effect of blank holder force on the stamp forming behavior of non-crimp fabric with a chain stitch. Composites Science and Technology, 67(3), 357-366. http://dx.doi.org/10.1016/j. compscitech.2006.09.009.

15. Yin, H., Peng, X., Du, T., \& Chen, J. (2015). Forming of thermoplastic plain woven carbon composites: An experimental investigation. Journal of Thermoplastic Composite Materials, 28(5), 730-742. http://dx.doi.org/10.1177/0892705713503668.

16. Trudel-Boucher, D., Fisa, B., Denault, J., \& Gagnon, P. (2006). Experimental investigation of stamp forming of unconsolidated commingled E-glass/polypropylene fabrics. Composites Science and Technology, 66(3), 555-570. http://dx.doi.org/10.1016/j. compscitech.2005.05.036.

17. Haanappel, S. P., Ten Thije, R. H. W., Sachs, U., Rietman, B., \& Akkerman, R. (2014). Formability analyses of uni-directional and textile reinforced thermoplastics. Composites. Part A, Applied Science and Manufacturing, 56, 80-92. http://dx.doi org/10.1016/j.compositesa.2013.09.009.

18. Shirani, M., Agahi, A., Sadough, S. A., \& Biglari, F. R. (2006). Experimental and analytical analysis of thermoplastic reinforced composite sheet deep drawing. In Proceedings of the MATERIAUX (Vol. 1, No. 1). Dijon, France: French Federation of Materials.

19. Taflick, T., Maich, É. G., Ferreira, L. D., Bica, C. I. D., Rodrigues, S. R. S., \& Nachtigall, S. M. B. (2015). Acacia bark residues as filler in polypropylene composites. Polímeros: Ciência e Tecnologia, 25(3), 289-295. http://dx.doi.org/10.1590/01041428.1840 .

20. Jayaraman, P., \& kumar, L. M. (2014). Multi-response optimization of machining parameters of turning AA6063 T6 aluminium alloy using grey relational analysis in Taguchi method. Procedia Engineering, 97, 197-204. http://dx.doi org/10.1016/j.proeng.2014.12.242.

21. Suresh, S., \& Senthil Kumar, V. S. (2016). Influence of process parameters on the forming behaviour of thermoplastic composite: an experimental approach. International Journal of Printing. Packaging \& Allied Sciences, 4(3), 1553-1564.

22. Mohaiyiddin, M. S., Lin, O. H., Akil, H. M., Yee, T. G., Adik, N. N. A. N., \& Villagracia, A. R. (2016). Effects of polypropylene methyl polyhedral oligomeric silsesquioxanes and polypropylene-grafted maleic anhydride compatibilizers on the properties of palm kernel shell reinforced polypropylene biocomposites. Polímeros: Ciência e Tecnologia, 26(3), 228235. http://dx.doi.org/10.1590/0104-1428.2038.

23. Zhang, Q., Cai, J., \& Gao, Q. (2014). Simulation and experimental study on thermal deep drawing of carbon fiber woven composites. Journal of Materials Processing Technology, 214(4), 802-810. http://dx.doi.org/10.1016/j.jmatprotec.2013.11.024.

24. Isogawa, S., Aoki, H., \& Tejima, M. (2014). Isothermal forming of CFRTP sheet by penetration of hemispherical punch. Procedia Engineering, 81, 1620-1626. http://dx.doi. org/10.1016/j.proeng.2014.10.201.

25. Davey, S., Das, R., Cantwell, W. J., \& Kalyanasundaram, S. (2013). Forming studies of carbon fibre composite sheets in dome forming processes. Composite Structures, 97, 310-316. http://dx.doi.org/10.1016/j.compstruct.2012.10.026.

26. Bhattacharyya, D., Bowis, M., \& Jayaraman, K. (2003). Thermoforming woodfibre-polypropylene composite sheets. 
Composites Science and Technology, 63(3), 353-365. http:// dx.doi.org/10.1016/S0266-3538(02)00214-2.

27. Sadighi, M., Rabizadeh, E., \& Kermansaravi, F. (2008). Effects of laminate sequencing on thermoforming of thermoplastic matrix composites. Journal of Materials Processing Technology, 201(1), 725-730. http://dx.doi.org/10.1016/j.jmatprotec.2007.11.239.

28. Vijayan, S., Raju, R., \& Rao, S. R. K. (2009). Friction stir welding of Al-Mg alloy: comparison of process parameter optimization between single and multi response using Taguchi methodology. International Journal of Applied Engineering Research, 4(5), 709-725. Retrieved in 2017, November 28, from https://www.ripublication.com/ijaerv4/ijaerv4n5_7.pdf

29. Haq, A. N., Marimuthu, P., \& Jeyapaul, R. (2008). Multi response optimization of machining parameters of drilling $\mathrm{Al} / \mathrm{SiC}$ metal matrix composite using grey relational analysis in the Taguchi method. International Journal of Advanced Manufacturing Technology, 37(3), 250-255. http://dx.doi. org/10.1007/s00170-007-0981-4.

30. Kuo, Y., Yang, T., \& Huang, G. W. (2008). The use of a greybased Taguchi method for optimizing multi-response simulation problems. Engineering Optimization, 40(6), 517-528. http:// dx.doi.org/10.1080/03052150701857645.

31. Tong, L. I., Su, C. T., \& Wang, C. H. (1997). The optimization of multi-response problems in the Taguchi method. International
Journal of Quality \& Reliability Management, 14(4), 367-380. http://dx.doi.org/10.1108/02656719710170639.

32. Yang, T., \& Chou, P. (2005). Solving a multiresponse simulation-optimization problem with discrete variables using a multiple-attribute decision-making method. Mathematics and Computers in Simulation, 68(1), 9-21. http://dx.doi. org/10.1016/j.matcom.2004.09.004.

33. Sathiya, P., Aravindan, S., \& Noorul Haq, A. (2006). Optimization for friction welding parameters with multiple performance characteristics. International Journal of Mechanics and Materials in Design, 3(4), 309-318. http://dx.doi.org/10.1007/ s10999-007-9037-z.

34. Vijayan, S., Raju, R., \& Rao, S. K. (2010). Multiobjective optimization of friction stir welding process parameters on aluminum alloy AA 5083 using Taguchi-based grey relation analysis. Materials and Manufacturing Processes, 25(11), 1206-1212. http://dx.doi.org/10.1080/10426910903536782.

35. Panneerselvam, R. (2012). Design and analysis of experiments. India: PHI Learning (P) Ltd.

Received: Nov. 28, 2017 Revised: Mar: 18, 2018 Accepted: May 15, 2018 